\title{
Association between polypharmacy and the adherence to pharmacological treatment in patients with diabetes
}

\author{
Associação entre polifarmácia e adesão ao tratamento farmacológico em pacientes com \\ diabetes
}

Kiarelle Lourenço Penaforte ${ }^{1}$, Samila Torquato Araújo ${ }^{2}$, Virginia Oliveira Fernandes ${ }^{2}$, Islene Victor Barbosa ${ }^{1}$, Virna Ribeiro Feitosa Cestari ${ }^{3}$, Renan Magalhães Montenegro Júnior ${ }^{2}$

Objective: to evaluate the occurrence of polypharmacy and its association with the adherence to the pharmacological treatment in patients with diabetes mellitus type 2. Methods: cross-sectional study conducted with 235 patients with diabetes mellitus type 2 through interview about the demographic and clinical data, drug therapy prescribed and adherence to treatment. To analyze the data, we used Student t-tests and Chi-square, with significance level $p<0.05$. Results: polypharmacy was evidenced in $88.4 \%$ of cases with a predominance of moderate level. An average of 7.5 pills per person among the 19 types of prescribed drugs were used. Adherence to prescribed therapy was reported by $88.2 \%$ of patients evaluated and there was no association with polypharmacy $(\mathrm{p}=0.266)$. Conclusion: it was verified that polypharmacy is a condition of high prevalence and is not associated with worse adherence to therapy.

Descriptors: Diabetes Mellitus, Type 2; Therapeutics; Polypharmacy; Medication Adherence; Nursing.

Objetivo: avaliar a ocorrência da polifarmácia e sua associação com a adesão ao tratatamento farmacológico em pacientes com diabetes mellitus tipo 2. Métodos: estudo transversal realizado com 235 portadores de diabetes mellitus tipo 2 por meio de entrevista sobre os dados sociodemográficos e clínicos, a terapêutica medicamentosa prescrita e a adesão ao tratamento. Para análise dos dados foram utilizados os testes $\mathrm{t}$ de Student e quiquadrado, com nível de significância p<0,05. Resultados: a polifarmácia foi evidenciada em $88,4 \%$ dos casos com predomínio da moderada. Foram utilizados, em média, 7,5 comprimidos por pessoa dentre os 19 tipos de fármacos prescritos. A adesão à terapêutica prescrita foi relatada por $88,2 \%$ dos pacientes avaliados e não houve associação com a polifarmácia $(\mathrm{p}=0,266)$. Conclusão: foi verificado que a polifarmácia é uma condição de elevada prevalência e não está associada a pior adesão à terapêutica.

Descritores: Diabetes Mellitus Tipo 2; Terapêutica; Polimedicação; Adesão à Medicação; Enfermagem.

\footnotetext{
${ }^{1}$ Universidade de Fortaleza. Fortaleza, CE, Brazil.

${ }^{2}$ Universidade Federal do Ceará. Fortaleza, CE, Brazil.

${ }^{3}$ Universidade Estadual do Ceará. Fortaleza, CE, Brazil.
} 


\section{Introduction}

The prevalence of Diabetes Mellitus (DM) is increasing dramatically worldwide and reaching epidemic proportions. It is estimated that there are 285 million people with DM and this number will rise to 438 million by the year 2030. The human, social and economic consequences are devastating and impacting negatively on socially and economically developing countries ${ }^{(1)}$.

Diabetes Mellitus type 2 (DM2) appears as a pandemic and a challenge for health systems around the world. The ageing population, increasing urbanization and the adoption of unhealthy lifestyles have a great responsibility on the worldwide increasing incidence and prevalence of this pathology ${ }^{(2)}$.

DM2 stands out as a potential clinical predictor for the aggravation of clinical cases and an increase in the length of stay in hospital. A study points that diabetes increases the cost with very expensive medicines throughout life, although it is associated with a reduced life expectancy. So, it is observed that the decrease in long-term medical costs is related to lower investments in prevention ${ }^{(3)}$.

On the genesis of chronic complications, the most important and challenging for health professionals who care for patients with diabetes is blood glucose control, which is closely related to the compliance with the prescribed treatment and covers medicinal and not medicinal measures that can be applied separately or together ${ }^{(4)}$.

The effective results of chronic diseases management depend in great part of the patient compliance to treatment, which also depends, among other things, on the provision of methods, tools and specific incentives and, especially, the degree of involvement of the patient and the caregiver to the therapeutic plan follow-up/compliance and to understand its importance $^{(5)}$.

The issue of non-adherence to prescribed drug treatment is also of utmost importance in recent decades and is being included in the list of concerns of health professionals along with other factors that influence the rational use of therapeutic resources. It is known that with the need of using many drugs there are continuous difficulties to follow the prescription, especially among elderly people ${ }^{(6)}$. Currently, the number of drugs adopted in establishing a normoglycemia in diabetics is huge. However, this scenario is the opposite before the non-adherence of these patients to such drugs ${ }^{(7)}$. In the face of this reality, the pharmacology adherence comes as a relevant public health theme.

Before the exposed, we can see the relevance of developing a study about diabetes, including the polypharmacy and drug adherence, since the chronicity of the disease associated with the characteristics of the therapeutic treatment can interfere in the patients' adhesion. Such data can contribute to achieve therapeutic objectives required to control this disease.

Therefore, this study aimed to evaluate the occurrence of polypharmacy and its association with the pharmacological treatment adherence in patients with diabetes mellitus type 2 .

\section{Methods}

This is a cross-sectional and exploratory study conducted in two public health units in the city of Fortaleza, CE, Brazil. The population characteristics and therapeutic adhesion were investigated as well as its correlation with polypharmacy. 235 patients with DM2 were selected from medical appointments between January and December 2012.

Individuals included were adults ( $\geq 18$ years) with a diagnosis of diabetes melittus type 2 under medical follow-up in these places. The diagnosis was established by analyzing the patients' records, clinical criteria (weight, symptoms, need for insulin, laboratory tests) and the medical staff. Patients with a diagnosis of gestational diabetes and DM type 1 were excluded as well as patients with clinical conditions that might interfere with data collection or made use of illicit drugs. 
The data related to the variables of socio-demographic, clinics, drug therapy and treatment adherence factors, were obtained from semi-structured interview. On this occasion, the polypharmacy was determined based on average use and distribution of medicines and studies concerning the subject were considered. Polypharmacy was delimited as the use of two or more medicines and stratified in low polypharmacy -2 to 3 medicines, moderate- 4 to 5 drugs and high - more than 5 drugs $^{(8)}$.

The frequency of drug adherence was measured from the self-report method. Two categories of treatment adherence were established, the first relates to oral therapy: (1) treatment adherence: when the patient follows at least $90.0 \%$ of the proposed treatment; and (2) non-adherence: when the patient follows less than $90.0 \%$ of the treatment.

To determine the adhesion of the patients with DM type 2 to drug therapy, we asked the following question Do you take this medicine every day according to the medical prescription? For each drug corresponds answers with respective percentages: always (medicine use of $100.0 \%$ ), frequently (medicine use of $90.0 \%$ ), sometimes (medicine use of $50.0 \%$ ), rarely (medicine use of $20.0 \%$ ) and never corresponded to $0 \%$, i.e., the patient doesn't use the prescribed medicine.

The second category of adherence relates to insulin therapy and the measure was verified from the following question: do you take insulin daily according to the medical prescription? It was considered the answer yes/regular as treatment adherence; and yes/irregular or no as non-adherence.

The database was developed in Excel program and subsequently transported to the Stata program. Descriptive statistical analysis was performed to calculate the means \pm standard deviation with normal distribution of the data, which was organized in tables. The differences between the means of the continuous variables were analyzed by the Student's t-test with the software Graph Pad Prism. For the inferential analysis we considered statistically significant value $\mathrm{p}<0.05$.

The study complied with the formal requirements contained in the national and international regulatory standards for research involving human beings.

\section{Results}

According to Table 1, 162 (68.9\%) participants were female. About the age group, the patients were between 28 and 90 years old distributed in the following age groups: 28 to 40,13 (5.0\%); 41 to 59,34 (14.0\%); 51 to 60,79 (34.0\%); 61 to $70,58(25.0 \%)$; 71 to $80,33(14.0 \%)$ and 81 to $90,18(8.0 \%)$; the average age was 59.3 years old (standard deviation \pm 12.7). About marital status, 132 (56.2\%) were married or living in a stable relationship, while 39 (16.6\%) were single; 37 (15.7\%) widowed; and 27 (11.4\%) divorced.

About the occupation of this participants, 98 (41.7\%) were retired; 39 (16.6\%) housewives; 31 (13.1\%) self-employed; 24 (10.2\%) employed; 16 (6.8\%) pensioners; three (1.2\%) domestic servants; and $15(6.3 \%)$ were unemployed. About years of schooling, 114 (48.4\%) had from 5 to 9 years; followed by 10 to 12 years, 71 (30.2\%). The family income predominant was of one salary, 93 (39.5\%). The presence of a support network was mentioned by 145 (61.7\%) of the participants.

With respect to the prescribed drug treatment we observed that oral antidiabetics were mostly mentioned, with a predominance of biguanides and sulfonylureas, in which 167 (71.0\%) used metformin; 52 (22.1\%) glibenclamide; 31 (13.1\%) gliclazide; two $(0.8 \%)$ glimepiride; and one $(0.4 \%)$ acarbose. It was also verified the use of long-acting and super-fast insulins to glycemic control, in which 115 (48.9\%) took the NPH and 81 (34.4\%) used the regular insulin. About monotherapy, 58 (25.5\%) individuals were using only oral antidiabetics and 44 (18.7\%) used 
only insulin. Metformin as monotherapy was verified in $43(19.2 \%)$ individuals, followed by sulfonylureas, in $15(6.3 \%)$.

Medicinal associations were observed in 53.0\% of respondents, in which the use of metformin with some kind of insulin was more frequent, 55 (23.4\%). Regarding the use of oral antidiabetics associated with insulin, we found that 14 (5.9\%) patients used the combination of insulin with sulphonylurea and metformin and only one $(0.4 \%)$ combined insulin with acarbose and metformin.

From the sample, 210 (88.4\%) participants used more than two drugs, while 25 (11.6\%) used only one medicine.

With respect to the classification of polypharmacy, we found that $22(9.3 \%)$ realized high polypharmacy; 95 (40.4\%), moderate; 79 (33.6\%) low; and 39 $(16.5 \%)$ did not follow any kind of polypharmacy. As to the quantity of pills used daily, it was demonstrated that the number of pills ranged from one to 20 , in a total of 19 prescription drugs. The overall average per person was 7.5 pills. Patients in high polypharmacy used 10 pills; in moderate they used, on average, 8.1 pills; and in low, 4.8 pills. Patients without polypharmacy used an average of 1.3 pills.

The analysis of the treatment adherence of DM type 2 was considered adequate in $88.2 \%$ of the patients evaluated and the non-adherence was present in $11.8 \%$.

In the drug treatment 187 (92.5\%) individuals who used oral antidiabetics follow the treatment. 104 (88.9\%) of the patients who used insulin follow the prescriptions.

About high polypharmacy, 47 (94.0\%) patients follow the drug treatment. In moderate, 72 (81.8\%) followed it; and 60 (84.5\%) in the low polypharmacy. The ones who did not use polypharmacy, 22 (84.6\%) followed the proposed treatment, according to Table 2.
Table 1 - Characteristics of the studied population according to socio-demographic variables correlated with the use of polypharmacy

\begin{tabular}{|c|c|c|}
\hline \multirow[t]{2}{*}{ Variables } & \multirow{2}{*}{$\begin{array}{c}\begin{array}{c}\text { With } \\
\text { polypharmacy }\end{array} \\
\mathrm{n}(\%)\end{array}$} & $\begin{array}{c}\text { Without } \\
\text { polypharmacy }\end{array}$ \\
\hline & & n (\%) \\
\hline \multicolumn{3}{|l|}{ Gender } \\
\hline Feminine & $152(72.4)^{\mathrm{a}}$ & $10(40.0)$ \\
\hline Masculine & $58(27.6)^{a}$ & $15(60.0)$ \\
\hline \multicolumn{3}{|l|}{ Marital status } \\
\hline Married & $111(52.8)$ & $11(40.0)$ \\
\hline Single & 33 (15.7) & $6(24.0)$ \\
\hline Widowed & $34(16.2)$ & $3(12.0)$ \\
\hline Divorced & $25(12.0)$ & $2(8.0)$ \\
\hline Stable union & $7(3.3)$ & $3(12.0)$ \\
\hline \multicolumn{3}{|l|}{ Occupation } \\
\hline Retired & $89(42.4)^{b}$ & $9(36.0)$ \\
\hline Housewives & $38(19.0)^{b}$ & $1(4.0)$ \\
\hline Self-employed & $25(12.0)^{\mathrm{b}}$ & $6(24.0)$ \\
\hline Employed & $20(9.5)^{\mathrm{b}}$ & $4(16.0)$ \\
\hline Pensioner & $15(7.1)^{\mathrm{b}}$ & $1(4.0)$ \\
\hline Domestic servant & $3(1.4)^{\mathrm{b}}$ & - \\
\hline Unemployed & $13(6.2)^{\mathrm{b}}$ & $2(8.0)$ \\
\hline Others & $7(3.3)^{b}$ & $2(8.0)$ \\
\hline \multicolumn{3}{|l|}{ Education (years) } \\
\hline$<5$ & $14(6.7)^{*}$ & - \\
\hline $5-9$ & $105(50.0)^{*}$ & $9(36.0)$ \\
\hline $9-12$ & $61(29.0)^{*}$ & $10(40.0)$ \\
\hline$>12$ & $12(5.7)^{*}$ & $4(16.0)$ \\
\hline Non-determined & $18(8.6)^{*}$ & $2(8.0)$ \\
\hline \multicolumn{3}{|c|}{ Family income (minimum wage) } \\
\hline$<1$ & $16(7.6)^{*}$ & $3(12.0)$ \\
\hline 1 & $85(40.5)^{*}$ & $8(32.0)$ \\
\hline $2-3$ & $81(38.6)^{*}$ & $9(36.0)$ \\
\hline $3-5$ & $16(7.6)^{*}$ & $4(16.0)$ \\
\hline$>5$ & $8(3.8)^{*}$ & $1(4.0)$ \\
\hline \multicolumn{3}{|l|}{ Support network } \\
\hline Yes & $132(62.9)^{*}$ & $13(52.0)$ \\
\hline No & $78(37.1)^{*}$ & $12(48.0)$ \\
\hline Total & $210(100.0)$ & $25(100.0)$ \\
\hline
\end{tabular}


Table 2 - Association between polypharmacy and drug adherence among the participants of this research

\begin{tabular}{lccc}
\hline \multirow{2}{*}{ Polypharamcay } & Adherence & Non-adherence & \multirow{2}{*}{$\mathbf{p}$} \\
\cline { 2 - 3 } & $\mathbf{n}(\%)$ & $\mathbf{n}(\%)$ & \\
\hline High & $47(94.0)$ & $3(6.0)$ & \\
Moderate & $72(81.8)$ & $16(18.2)$ & \\
Low & $60(84.5)$ & $12(15.5)$ & $0.266^{*}$ \\
Without polypharmacy & $22(84.6)$ & $3(15.4)$ & \\
Total & $201(85.5)$ & $34(14.5)$ & \\
${ }^{*}$ Chi Square test & & &
\end{tabular}

As a study limitation we can mention the use of self-report to measure the adherence to drug treatment, which promotes reminiscent error and may involve a certain degree of imprecision in the estimates obtained. We can also add the lack of consensus in the literature about polypharmacy classification.

The DM is usually diagnosed in adults and, therefore, the exposure to the disease increases after reaching old-age ${ }^{(9)}$. A similar result was obtained in an international study in which DM prevalence occurred in individuals between 60 and 65 years old (63.2\%) and presented an upward curve with positive and significant relation ${ }^{(10)}$. The association between age and this condition is also found in the national literature. A recent study showed that individuals with 45 years old or more have more chances of developing the disease $(\mathrm{p}<0.001 \text {; Odds ratio }=3.00)^{(2)}$.

In this study, most of the participants were married (51.9\%) and with support network (61.7\%). These findings may contribute to the implement and access therapies accepted by patients. Family members can help them manage medications, minimizing errors and reducing the risk factors for non-adherence to the treatment. In this way, the high rate of accompanied individuals may justify the incentive to look for healthcare ${ }^{(11)}$.

About education, (48.4\%) reported having studied between 5-9 years, which may contribute to the high rate of adherence to drug treatment, that provides a better understanding of prescription and facilitates to follow it properly. Greater understanding of the users about the therapy can help them get better control this situation and, possibly, have lower risks of developing late complications of $\mathrm{DM}^{(12)}$. The data showed that as family income, $77.8 \%$ had a monthly income between one and three minimum wages, which makes it possible to infer it is a group of unfavorable socioeconomic conditions. This result was expected since the study scenario corresponded to State units of primary health care where citizens in a less favorable financial situation use the services.

When investigated the specific drug treatment to DM2, it was found that metformin was the most widely used medication (71.0\%), followed by the sulfonylureas (36.4\%). About monotherapy, (25.5\%) of the population used only oral antidiabetics and (18.7\%) used only insulin. In DM, the isolated use of metformin lowers blood glucose in $(25.0 \%)$ or 60 to $70 \mathrm{mg} / \mathrm{dl}$ and glycated hemoglobin in 1.5 to $2.0 \%$. It has been shown that the effectiveness of glycemic control for metformin is similar of the sulfonylurea, and it is associated with weight reduction, so important in the DM2 ${ }^{(13)}$.

The variety and combinations of antihypertensive, antilipemic and antidiabetic medications in this study was high, mostly associated with captopril, hydrochlorothiazide, metformin and simvastatin. The use of only two concurrent anti-diabetic drugs occurred in (23.4\%) of diabetics prescription in polytherapy, which is recommended by the Ministry of health of Brazil when the associations are appropriate and, therefore, should be prescribed in a rational manner according to the needs of each individual ${ }^{(13)}$.

In this sense, polypharmacy is a natural consequence in medical care, because of the emergence of complications of the disease under study. Usually, multiple drugs treatments are needed to control hyperglycemia and metabolic risk associated with comorbidities, such as hypertension and hyperlipidemia. Patient adherence to medical prescription is crucial to achieve metabolic control ${ }^{(14)}$.

In this study, adherence to drug treatment prevailed in $(88.2 \%)$ of the population. This converges 
with a cross research performed in the clinic of Endocrinology with 60 diabetic patients, in which adherence to the prescribed drug treatment was (87.0\%) ${ }^{(15)}$. Similar values were checked in another study, with the same users' profile, developed with 423 patients, which showed (84.4\%) of adherence ${ }^{(16)}$.

A cross-sectional study developed in the Diabetes clinic of tertiary healthcare, observed that regardless of the type of drug prescribed, people with DM2 seem to perform more frequently the activity of self-care on the medication than those related to lifestyle changes. The adhesion behaviors are not stable and may change over time, therefore, they require regular measurements in order to evaluate the effectiveness of the therapy ${ }^{(17)}$.

The lack of adherence to the treatment for diabetes control is the main cause for the development of acute, chronic complications and reduced quality of life. They represent individual, social, economic costs to the patient, the family, health institutions and society $^{(14)}$.

The dosing schedule compliance is directly related to the therapeutic efficacy, and the therapy adherence is fundamental, which is in accordance with the oral and written instructions healthcare professional give about the pharmacological treatment. Having this in mind, the clinical history of the patient should be carefully considered to identify the best model of polypharmacy and to investigate questions about drug interactions, which are particularly important ${ }^{(5)}$.

It was observed that $(86.7 \%)$ of patients using polypharmacy followed the treatment. Despite the average consumption of medicines according to the study was 7.5 pills per person there was a significant difference when compared to the treatment adherence. However, it must be considered that (62.9\%) of the sample was composed of individuals who had a support network responsible for conducting the pharmacological treatment, which may have negatively impact on the result.
Trying to maximize the benefits of polypharmacy, it is possible to carry out appropriate drugs combinations, which reduces the symptoms of the disease and slows down its progression reducing complications and improving the quality of life ${ }^{(6)}$. However, polypharmacy needs to be controlled effectively, because when not correctly prescribed it can bring serious health risks for the patient.

In general, compliance with the pharmacological treatment represents a complex interaction between the three pillars: social factors, those relating to the patient and healthcare professionals. Aspects such as cultural and socioeconomic condition, age, sex, marital status (socio-demographic factors); prescribed drug type, number of pills a day (factors relating to drug treatment); time of illness, diseases and medicines (clinical factors); and guidelines received from health professionals are related to the success or failure of adherence to pharmacological regimens ${ }^{(12)}$.

A rational combined therapy can maximize the control of target parameters, along with the glycemic control to minimize the risks, reduce the chances of comorbidities emerge and develop and enables to reduce the healthcare services costs with these patients, as well as maximizes the benefits of polypharmacy, which ends up increasing the patients' quality of life.

\section{Conclusion}

The practice of polypharmacy was evidenced among the patients with DM, but the frequency of daily medications was not observed as a non-adherence factor. Although we verified an elevated level of adherence to the prescribed therapy to control DM, we observed unsatisfactory metabolic control. The polypharmacy was associated to the risks involving the occurrence of adverse reactions and interactions and the benefits related to a better quality of life, which should be considered in the context of the individual, pondering the biological variations of each patient. 


\section{Collaborations}

Penaforte KL contributed to the conception and design or analysis and interpretation of data. Araújo ST, Fernandes VO, Barbosa IV, Cestari VRF e Montenegro Júnior RM contributed writing the article and the relevant review of intellectual content. All the authors contributed to the final approval of the version to be published.

\section{References}

1. Gelaw BK, Mohammed A, Tegegne GT, Defersha AD, Fromsa M, Tadesse E, et al. Nonadherence and contributing factors among ambulatory patients with antidiabetic medications in Adama referral hospital. J Diabetes Res. 2014; 2014:617041. doi: http://dx.doi.org/10.1155/2014/617041

2. Marinho NBP, Vasconcelos HCA, Alencar AMPG, Almeida PC, Damasceno MMC. Risk for type 2 diabetes mellitus and associated factors. Acta Paul Enferm. 2013; 26(6):569-74. doi: http://dx.doi. org/10.1590/S0103-21002013000600010

3. Zhuo X, Zhang P, Barker L, Albright A, Thompson TJ, Gregg E. The lifetime cost of diabetes and its implications for diabetes prevention. Diabetes Care. 2014; 37(9):2557-64. doi: http://dx.doi. org/10.2337/dc13-2484

4. Bruderer SG, Bodmer M, Jick SS, Meier CR. Poorly controlled type 2 diabetes mellitus is associated with a decreased risk of incident gout: a population-based case-control study. Ann Rheum Dis. 2015; 74(9):1651-8. doi: http://dx.doi. org/10.1136/annrheumdis-2014-205337

5. Dossa AR, Grégoire JP, Lauzier S, Guénette L, Siroius C, Moisan J. Association between loyalty to community pharmacy and medication persistence and compliance, and the use of guidelinesrecommended drugs in type 2 diabetes: a cohort study. Medicine. 2015; 94(27):e1082. doi: http:// dx.doi.org/10.1097/MD.0000000000001082

6. Carvalho MFC, Romano-Lieber NS, BersgtenMendes G, Secoli SR, Ribeiro E, Lebrão ML, et al. Polifarmácia entre idosos do Município de São Paulo - Estudo SABE. Rev Bras Epidemiol. 2012; 15(4):817-27. doi: http://dx.doi.org/10.1590/ S1415-790X2012000400013
7. Araújo MFM, Araújo TM, Alves PJS, Veras VS, Zanetti ML, Damasceno MMC. Uso de medicamentos, glicemia capilar e índice de massa corpórea em pacientes com diabetes mellitus. Rev Bras Enferm. 2013; 66(5):709-14. doi: http://dx.doi. org/10.1590/S0034-71672013000500011

8. Silva AL, Ribeiro AQ, Klein CH, Acurcio FA.Utilização de medicamentos por idosos brasileiros, de acordo com a faixa etária: um inquérito postal. Cad Saúde Pública. 2012; 28(6):1033-45. doi: http://dx.doi. org/10.1590/S0102-311X2012000600003

9. Farmer A, Hardeman W, Heghes D, Prevost AT, Kim Y, Craven A, et al. An explanatory randomized controlled trial of a nurse-led, consultation-based intervention to support patients with adherence to taking glucose lowering medication for type 2 diabetes. BMC Fam Pract. 2012; 5(13):30. doi: https://doi.org/10.1186/1471-2296-13-30

10. Faria HTG, Rodrigues FFL, Zanetti ML, Araújo MFM, Damasceno MMC. Factors associated with adherence to treatment of patients with diabetes mellitus. Acta Paul Enferm. 2013; 26(3):231-7. doi: http://dx.doi.org/10.1590/ S0103-21002013000300005

11. Libman IM, Miller KM, DiMeglio LA, Bethin KE, Katz ML, Shah A, et al. Effect of metformin added to insulin on glycemic control among overweight/obese adolescents with type 1 diabetes: a randomized clinical trial. JAMA. 2015; 314(21):2241-50. doi: http://dx.doi. org/10.1001/jama.2015.16174

12. Guidoni CM, Borges APS, Freitas O, Pereira LRL. Prescription patterns for diabetes mellitus and therapeutic implications: a population-based analysis. Arq Bras Endocrinol Metab. 2012; 56(2):120-7. doi: http://dx.doi.org/10.1590/ S0004-27302012000200005

13. Ministério da Saúde (BR). Secretaria de Atenção à Saúde. Departamento de Atenção Básica. Estratégias para o cuidado da pessoa com doença crônica: diabetes mellitus [Internet]. 2013 [citado 2017 jun 13]. Disponível em: http://bvsms.saude. gov.br/bvs/publicacoes/estrategias_cuidado_ doenca_cronica_diabetes_mellitus.pdf 
14. Oliveira MSS, Oliveira JCC, Amorim MÊS, Otton R, Nogueira MF. Evaluation of therapeutic adherence of patients with diabetes mellitus type 2. Rev Enferm UFPE on line [Internet]. 2014 [cited 2017 Jun 13]. 8(6):1692-701. Available from: https:// periodicos.ufpe.br/revistas/revistaenfermagem/ article/viewFile/13643/16502

15. Faria HTG, Santos MA, Arrelias CCA, Rodrigues FFL, Gonela JT, Teixeira CRS, Zanetti ML. Adherence to diabetes mellitus treatments in family health strategy units. Rev Esc Enferm USP. 2014; 48(2):257-63. doi: http://dx.doi.org/10.1590/ S0080-623420140000200009
16. Coelho ACM, Villas Boas LCG, Gomides DS, FossFreitas MC, Pace AE. Self-care activities and their relationship to metabolic and clinical control of people with diabetes Mellitus. Texto Contexto Enferm. 2015; 24(3):697-705. doi: http://dx.doi. org/10.1590/0104-07072015000660014

17. Sgnaolin V, Figueiredo AEPL. Adesão ao tratamento farmacológico de pacientes em hemodiálise. J Bras Nefrol. 2012; 34(2):109-16. doi: http://dx.doi. org/10.1590/S0101-28002012000200002 